16. This work was supported by the University of Uppsala and The Norwegian Research Council for the Science and Humanities.

17. Professor G. Rooth and Professor C. H. deVerdier, University Hospital Uppsala, have contributed with valuable ideas and support to this work.
18. Requests for reprints should be addressed to: O. D. Saugstad, M.D., Institute for Surgical Research, Rikshospitalet, Oslo I, Norway.

19. Accepted for publication March 13, 1975.

\title{
Growth and Skeletal Maturation in Asthmatic Children: Effect of Corticosteroid Treatment
}

\author{
HELEN G. MORRIS ${ }^{(25)}$ \\ Children's Asthma Research Institute and Hospital, and the National Jewish Hospital and Research Center, Denver, Colorado, USA
}

\section{Extract}

The effects of corticosteroid treatment on growth and skeletal maturation were evaluated in 189 children with severe asthma who were referred for care at a residential treatment center. Height age on admission was significantly retarded in $8-10 \%$ of patients who had received little corticosteroid treatment previously and in $35 \%$ of patients who had taken steroids daily for more than 2 years. Children who had been treated with steroids intermittently or on alternate days were comparable to those who had taken steroids rarely. During an average residential period of 17 months, patients whose daily steroid treatment was discontinued had a relative gain in height age of 5 months; children who were started on daily steroids had a 5-month delay in growth. Evaluation of skeletal maturation at the time of admission revealed that skeletal age was more retarded than height age in the boys and less retarded than height age in the girls. During the period of residence, the changes in bone age paralleled the changes in height age.

\section{Speculation}

Suppression of growth is a frequent complication in asthmatic children who receive prolonged treatment with corticosteroids. In some patients the suppression of growth may result in permanent dwarfism. However, no information is currently available on the adult heights of patients who have received prolonged corticosteroid therapy during childhood.

It is well known that prolonged corticosteroid therapy in children may be associated with the inhibition of growth. However, there are still a number of unanswered questions with respect to the frequency and severity of the dwarfism induced by corticosteroids, the possible contributory influence of the underlying disease, and the likelihood of "catch-up" growth after corticosteroid therapy is discontinued. Additionally, more information is needed about the effects of corticosteroid treatment on the skeletal maturation of children without endocrine disease. In this study the influence of corticosteroid therapy on height and skeletal maturation was evaluated in a large population of children with asthma.

\section{MATERIALS AND METHODS}

\section{PATIENTS}

All children had severe asthma and had been referred for care at a residential treatment center in Denver. The study was based on a retrospective evaluation of two population groups: children in residence at the center in 1965 and those admitted in 1970. The ages of both groups (Table 1) ranged between 6 and 15 years, with a mean age of 11 . Most of the patients were Caucasian children from middle income families. The larger number of boys reflects the population at the treatment center.

The initial phase of the study was based on evaluation of height and skeletal maturation at the time of admission in 189 children. The number of subjects in this portion of the study permitted separate evaluation of the data in boys and girls.

The second phase of the study was based on evaluation of the changes in physical development during the period of residential care. For this purpose comparisons were made of height and skeletal ages at the time of admission and discharge in 76 children (49 boys and 27 girls). The duration of residential treatment ranged between 12 and 24 months with an average of 17 months. This portion of the study is largely based on data of children hospitalized during 1965.

\section{EXPERIMENTAL APPROACH}

To reduce bias in interpretation of data, the study was approached first by assessment of skeletal ages from radiographs of the left hand and wrist which had been obtained during the course of routine diagnostic evaluation (22). After the assessment of skeletal ages had been completed, the heights and weights of the patients at the time of the $x$-ray examinations were abstracted from the charts and recorded separately. The patients' charts were then reviewed without regard to the growth data and an assessment was made of the course and severity of the asthma and the history of steroid therapy.

\section{EVALUATION OF SKELETAL DATA}

Skeletal ages were determined by the author through comparison of radiographs of the left wrist with the standards in a 
Greulich-Pyle atias (9). In some instances the assessment of bone age was especially difficult because the maturation ages suggested by primary centers (carpals) were markedly delayed in comparison with the secondary (long bone) epiphyses. Although similar discrepancies in maturation have been observed in healthy children $(8,10)$, the frequency and severity of the imbalance appeared to be unusually great in our study population. Because of the imbalance, attempts to determine skeletal ages on the basis of all bones in the hands and wrists (18) sometimes resulted in low readings which could change markedly when subsequent films of the same patient were examined, if the extent of the imbalance decreased. For the purpose of this study, skeletal ages were therefore assigned on the basis of the more mature digital epiphyses rather than the less mature carpal ossification centers. Other investigators have also suggested that carpal ossification may be ignored in the assessment of maturation when the carpals differ markedly from the digits ( 1 , $15,16)$.

To evaluate the reproducibility of the bone age determinations, a group of 66 radiographs from 30 patients was reviewed by the author at the conclusion of the study, many months after the initial assessment of skeletal age. Comparison of the initial and follow up assessment of the 66 hand films, with bone ages ranging from 4.516 years, showed a mean difference between the two readings of 0.08 years; the standard deviation of the difference in the two determinations was \pm 0.30 years $\left(S D=\sqrt{\mathrm{d}^{2} / 2 \mathrm{~N}}\right)$. Re-evaluation of the magnitude of change in bone age in 35 paired films taken during the residential period revealed that the standard deviation of the differences in the two assessments was 0.36 years; mean difference $=0.15$ years.

The determination of height age was based on the mean heights of normal children in the lowa City study (19). The calculated difference between height age and chronologic age provided an indication of the amount of retardation in growth of each patient. Group data were evaluated by standard statistical methods (7). Weight was not used as an index of growth in this study because of the variable influence of corticosteroid treatment on total body weight and lean body mass.

\section{EVALUATION OF STEROID PROGRAM}

The program of corticosteroid treatment before admission was classified on the basis of frequency and duration into three broad categories: (1) "rare," no steroid or short courses administered infrequently; (2) "intermittent," steroid therapy given on alternate days or during many short courses, with periods of days or weeks of no steroid therapy for at least 2 years; (3) "frequent," daily treatment for at least 2 years (mean duration in the group 3.5 years) or frequent prolonged courses with only short periods off steroids for at least 3 years. Treatment could not be evaluated in relation to the steroid preparation or specific steroid dose.

Evaluation of the influence of steroid treatment during the period of residential care was based on data of children who could be separated clearly into 1 of 2 subgroups: (1) no steroid during residence or (2) daily steroids throughout the period of residence. In all instances prednisone was used for maintenance therapy. The majority of patients who required continued daily treatment with steroids received $10-20 \mathrm{mg} / 24 \mathrm{hr}$ prednisone. However, the exact dose varied from one patient to another and from one time to another. Additionally, there was considerable variability in the amount anf frequency of supplemental steroids (intravenous hydrocortisone or Solu-Medrol) given for treatment of acute episodes of asthma. The data in this study were therefore evaluated solely on the basis of whether or not steroid treatment was administered on a daily schedule. Because of the small size of the groups, no attempt was made to separate the data further in relation to the specific amounts of steroid given.

\section{RESULTS}

PHYSICAL GROWTH AND MATURATION AT TIME OF ADMISSION

Table I summarizes the overall age and developmental data of boys and girls admitted to the center in 1965 and 1970. The alterations in development were similar in the two groups, but children of both sexes were relatively shorter for age in 1970 than in 1965. The greater severity of growth retardation in the 1970 group may reflect the greater proportion of steroid-treated patients admitted to the center in recent years (6). In a few instances genetic or nutritional factors may have contributed to the short stature but in the majority of patients no causes for shortness could be found other than those related to asthma or corticosteroid treatment. The parents' heights were well within normal limits: fathers, 69.5 inches $\pm \operatorname{SD} 2.5(n=83)$; mothers, 63.9 inches $\pm \operatorname{SD} 2.9(n=87)$.

Table 2 summarizes the relationship between previous corticosteroid treatment and growth inhibition. Even when asthmatic children had received little or no corticosteroid therapy, there was a moderate delay of $7-8$ months in average height age. The magnitude of retardation in growth increased as the frequency of steroid therapy increased. The retardation in height age was comparable in boys and girls who had received similar programs of treatment. However, there was a marked difference in the bone maturation of the two sexes. In girls, the retardation of skeletal age was less than the delay in height age; in boys the delay in skeletal age was considerably greater than the alteration in height.

Evaluation of the distribution of patients whose heights were more than 2 SD below the mean for normal children of the same age and sex revealed that growth was retarded in $8-10 \%$ of the asthmatic children who had received little or no corticosteroid

Table 1. Physical development of children with chronic asthma at time of admission to residential treatment center ${ }^{1}$

\begin{tabular}{lcccc}
\hline & No. & $\begin{array}{c}\text { Chronologic age, } \\
\text { years } \pm \mathrm{SD}\end{array}$ & $\begin{array}{c}\text { Skeletal age, } \\
\text { years } \pm \mathrm{SD}\end{array}$ & $\begin{array}{c}\text { Height age, } \\
\text { years } \pm \mathrm{SD}\end{array}$ \\
\hline $\begin{array}{l}\text { Boys } \\
1965\end{array}$ & 61 & $11.29 \pm 2.46$ & $9.92 \pm 2.95^{2}$ & $10.44 \pm 2.97$ \\
1970 & $\frac{58}{119}$ & $10.83 \pm 2.38$ & $9.48 \pm 2.91^{2}$ & $9.70 \pm 2.80^{2}$ \\
Girls & & & & \\
1965 & 30 & $11.66 \pm 2.28$ & $10.63 \pm 2.51$ & $10.72 \pm 2.18$ \\
1970 & $\frac{40}{70}$ & $11.02 \pm 2.85$ & $10.34 \pm 3.16$ & $9.90 \pm 2.63$ \\
& & &
\end{tabular}

'Although similar alterations in development were observed in boys and girls, results in the smaller number of girls did not achieve statistical significance.

${ }^{2}$ Significantly different from chronologic age $(P<0.05$ to $<0.001)$.

Table 2. Relationship between growth inhibition and previous corticosteroid therapy: mean differences below chronologic age ${ }^{1}$ at time of admission (years $\pm S D$ )

\begin{tabular}{|c|c|c|c|c|c|c|c|}
\hline \multirow{2}{*}{$\begin{array}{c}\text { Steroid } \\
\text { treatment }^{2}\end{array}$} & \multirow[b]{2}{*}{ No. } & \multicolumn{3}{|c|}{ Skeletal age } & \multicolumn{3}{|c|}{ Height age } \\
\hline & & $\mathrm{Yr}$ & $\mathrm{SD}$ & $p$ & $\mathrm{Yr}$ & $\mathrm{SD}$ & $P$ \\
\hline \multicolumn{8}{|l|}{ Boys } \\
\hline Rare & 42 & 0.76 & 1.48 & $<0.01$ & 0.65 & 1.48 & $<0.01$ \\
\hline $\begin{array}{l}\text { Inter- } \\
\text { mittent }\end{array}$ & 44 & 1.24 & 1.14 & $<0.001$ & 0.81 & 1.11 & $<0.001$ \\
\hline Frequent & $\frac{33}{119}$ & 2.27 & 1.39 & $<0.001$ & 1.68 & 1.36 & $<0.001$ \\
\hline \multicolumn{8}{|l|}{ Girls } \\
\hline Rare & 29 & 0.61 & 0.69 & $<0.001$ & 0.62 & 1.09 & $<0.01$ \\
\hline $\begin{array}{l}\text { Inter- } \\
\text { mittent }\end{array}$ & 20 & 0.73 & 1.07 & $<0.01$ & 0.94 & 0.96 & $<0.01$ \\
\hline Frequent & $\frac{21}{70}$ & 1.29 & 1.36 & $<0.001$ & 1.80 & 1.24 & $<0.001$ \\
\hline
\end{tabular}

${ }^{1}$ Height and skeletal ages were significantly retarded in all groups.

${ }^{2}$ See Evaluation of Steriod Treatment under Methods. 
treatment. The incidence of growth inhibition was minimally altered by "intermittent" treatment with corticosteroids. However, when children had been given daily steroid therapy for prolonged periods, the frequency of growth inhibition rose to $35 \%$.

\section{CHANGE IN GROWTH AND MATURATION DURING PERIOD OF RESI- DENTIAL TREATMENT}

The influence of corticosteroid treatment on growth was further evaluated in 76 children who received residential treatment for an average period of 1.41 years ( 17 months). Children were separated into groups based on the programs of corticosteroid treatment before admission and during residence. As shown in Table 3, growth was assessed by comparison of the differences between height age and chronologic age at the time of admission and discharge. It was found that children whose steroid programs were not changed appreciably during residence maintained similar patterns of growth before and after admission. Thus, children in group $l$ who did not receive corticosteroid treatment were normal in size at the time of admission and grew at a normal rate during the residential period. Children in group IIa who had previously received steroids "intermittently" had minimal delay in growth at the time of admission and showed only a slight gain in height age of 2 months (relative to chronologic age) after corticosteroids were discontinued. The retardation of growth in group $I V b$, who had previously taken steroids "frequently," also did not change significantly during the period of daily steroid therapy at the institute.

There werc three groups $(I I b, I I I$, and $I V a)$ in which the differences between height and chronologic ages changed significantly during the residential period. In all three groups, the changes in growth were associated with major changes in the program of corticosteroid treatment. The relative changes in height age of the patients included in these groups are illustrated in Figure 1. Children in group $I I b$ whose daily steroid treatment was discontinued had acceleration of growth. During the residential period of 17 months (approximately 16 months after steroids were discontinued), the increase in height age exceeded the advance in chronologic age by an average of 0.39 years $(4.7$ months $), P<$ 0.01 . Conversely, 17 of the 21 patients in groups $I I I$ and $I V a$ who were started on daily steroid therapy exhibited further delay in growth during the period of residence. The magnitude of delay in growth was similar in children who had previously taken steroids "rarely" (group III, $P<0.02$ ) and in those who had taken steroids "intermittently" before admission (group IVa, $P<0.05$ ). In both groups, the average increase in height age was only 12.7 months during the 18 months of residence at the institute.

There was a fairly close correspondence between growth in height and skeletal maturation during the period of residence. In most groups, the average change in skeletal age during the residential period approached the differences observed in height ages (Table 3). However, the changes in rate of skeletal maturation

Table 3. Effect of steroid program on change in development during the period of residental care

\begin{tabular}{|c|c|c|c|c|c|c|c|c|c|c|c|}
\hline & \multicolumn{3}{|c|}{ Steroid program } & No. & $\begin{array}{l}\text { Years in } \\
\text { residence }\end{array}$ & \multicolumn{3}{|c|}{ Bone age ${ }^{l}$} & \multicolumn{3}{|c|}{ Height age ${ }^{1}$} \\
\hline Group I & Rare & None & 0 & 16 & 1.35 & 0.56 & 0.48 & +0.08 & 0.11 & 0.07 & +0.04 \\
\hline Group II & Intermittent & None & Decrease & 7 & 1.26 & 0.20 & 0.07 & +0.13 & 0.39 & 0.22 & +0.17 \\
\hline Group IV & Intermittent & Daily & Increase & 11 & 1.55 & 1.00 & 1.29 & -0.29 & 1.04 & 1.49 & $-0.45 \dagger$ \\
\hline & Frequent & Daily & 0 & $\frac{22}{76}$ & 1.41 & 1.97 & 2.13 & -0.16 & 1.50 & 1.75 & -0.25 \\
\hline
\end{tabular}

${ }^{1}$ Expressed as years of retardation in comparison with chronologic age.

${ }^{2}$ Change during residence: + : acceleration of growth; $-:$ progression of the growth retardation; $\uparrow$ : significant change in height age during residence. Figure 1 for individual values.

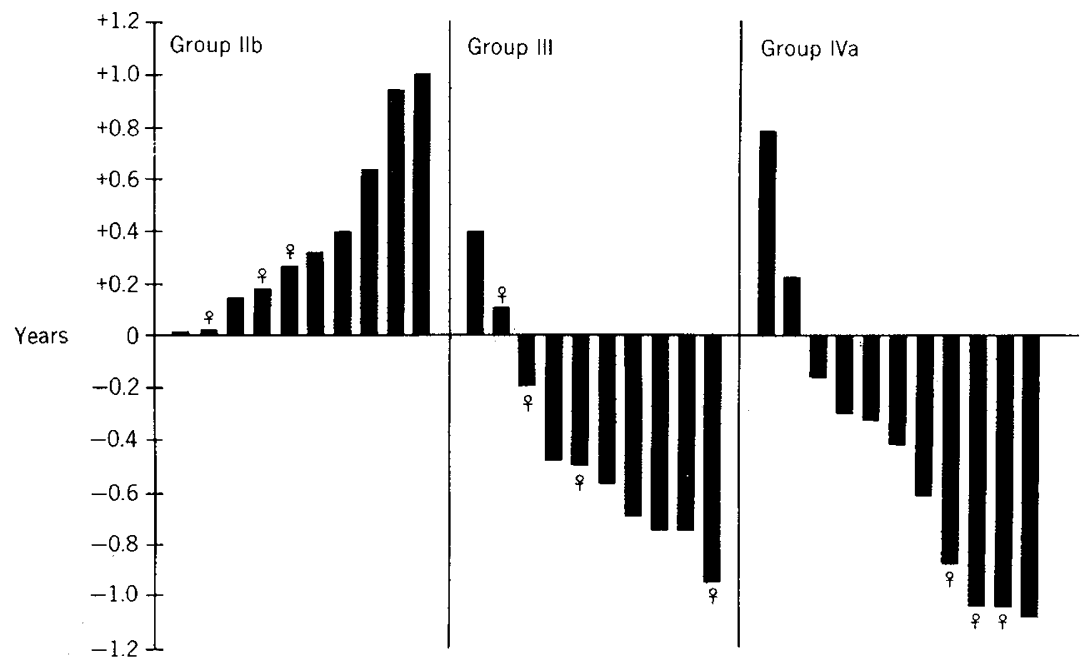

Fig. 1. Relative changes in height age during the period of residental care. Each column denotes a single subject. Girls are identified by the symbol (q); the remaining subjects were boys. The height of each column indicates the magnitude of change in height age (relative to chronologic age) during residence. Columns above the zero line represent acceleration of growth. Columns below the zero line represent worsening of the growth retardation. See text for description of groups and Table 3 for summary of group averages. 
during the period of residence did not achieve statistical significance.

Apart from the influence of corticosteroid therapy, there was a further suggestion in Table 3 that the severity of asthma also contributed to the growth retardation. Since the policy at the center is to discontinue corticosteroid therapy whenever possible, the daily administration of steroids during the period of residence may be taken as an indication of the severity of the disease or at least the difficulty in controlling symptoms. It was of interest therefore that in children with similar histories of previous therapy (groups $I$ and $I I I)$ and (groups IIa and IVa), the severity of the growth retardation at the time of admission appeared to vary in relation to the subsequent program of treatment at the institute. Although the differences in the small groups were not statistically significant, children who required daily steroid treatment at the institute had greater retardation of height and skeletal maturation at the time of admission than did those who could subsequently be managed without steroid therapy.

\section{DISCUSSION}

The present results demonstrate that suppression of growth is a frequent complication in children with severe asthma. In our population, growth was moderately delayed even in the absence of corticosteroid therapy. This may have resulted from the hypoxia which is often associated with severe asthma $(12,20)$ and which may persist even in the absence of symptoms (21). In addition, however, the program of corticosteroid treatment exerted a profound influence on skeletal growth and maturation. When steroids were administered intermittently, the delay in growth was only slightly greater than that observed in the absence of steroid medication. However, when steroids were given daily for prolonged periods, there was a marked increase in both the frequency and severity of the growth retardation.

During the period of residential care, the catch-up in growth observed in patients whose daily steroid therapy was discontinued was almost identical with the amount of delay in growth exhibited by children who were started on daily steroids. These observations suggest that in asthmatic patients, the time required for recovery from corticosteroid-induced suppression of growth may equal the time required for development of the growth retardation. The present results differ from those of others who have reported that the "catch-up" growth after the removal of an adrenal tumor or alleviation of other chronic diseases may approach 3 or 4 times the normal rate (13). Other investigators, however, have also observed that the "catch-up" growth after an illness (2) or after correction of congential heart defects $(3,5)$ may be relatively slow and incomplete. In our children, the persistence of asthma may have contributed to the slow catch-up in growth after discontinuation of daily corticosteroid treatment.

Evaluation of skeletal age was extremely difficult in our study population because of marked discrepancies in the maturation of the carpals as compared with the digital epiphyses. It was subsequently found that the larger discrepancies occurred in children who had received frequent corticosteroid treatment. When skeletal ages were assigned on the basis of the more mature ossification centers, the retardation of maturation was somewhat less severe than the retardation of growth in the girls; in boys, the changes in maturation appeared to be more severe than the retardation in height age. During the period of residential care, the changes in bone maturation paralleled the changes in height age in both sexes.

It has been suggested that corticosteroid treatment may cause greater suppression of bone age than height in children without endocrine disease $(4,11)$. The present data suggest such a trend in the boys, but not in the girls. Although it is possible that the effects of corticosteroid treatment on skeletal maturation differ in the two sexes, other factors may have contributed to the differences between the boys and the girls observed in this study. Schoen et al. (17) have reported that bone age appears to be excessively retarded in boys of short stature even when there is no apparent disease, suggesting that hand films from normal boys may not be suitable standards for evaluation of bone maturation in patients with altered patterns of growth. Additionally, there was a probable difference in the pubertal development of the two sexes. Although the mean ages of both groups were similar (11 years), girls of this age are approaching or have already entered puberty, while the majority of boys are prepubertal. A trend toward acceleration of bone maturation during early puberty may have contributed to the lesser degree of retardation in skeletal maturation of the girls. It was noteworthy, however, that the retardation of height remained comparable in both sexes.

The observations that catch-up growth after discontinuation of corticosteroid treatment is relatively show in asthmatic children and that the growth inhibition may not be reversed during the pubertal period suggest that prolonged steroid therapy during childhood might result in permanent dwarfism. Unfortunately, information concerning the adult heights of patients who have received prolonged steroid therapy during childhood is not currently available and is greatly needed. At the present time, the most beneficial approach to the prevention of steroid-induced dwarfism seems to involve manipulation of the program of corticosteroid treatment. Current observations suggest that the administration of corticosteroids on an intermittent or alternateday basis may be associated with considerably less suppression of growth than that which results from daily therapy (14).

\section{SUMMARY}

The program of corticosteroid therapy has a profound influence on the growth and skeletal maturation of children with asthma. The suppression of growth is also influenced by the severity of the asthma.

\section{REFERENCES AND NOTES}

1. Acheson, R. M., Fowler, G., Fry, E. I., Janes, M., Koski, K., Urbano, P., and van der Werff ten Bosch, J. J.: Studies in the reliability of assessing skeletal maturity from X-rays. Part I. Greulich-Pyle atlas. Human Biol., 35: 317 (1963).

2. Bauer, H.: Nephrosessyndrom und korperwachstum. Helv. Pediat. Acta, 9: 127 (1954).

3. Bayer, L. M., and Robinson, S. J.: Growth history of children with congenital heart defects. Size according to sex, age decade, surgical status, and diagnostic category. Amer. J. Dis. Child., 117: 564 (1969).

4. Blodgett, F. M., Burgin, L., Iezzoni, D., Gribetz, D., and Talbot, N. B.: Effect of prolonged cortisone treatment on the statural growth, skeletal maturation and metabolic status of children. New Engl. J. Med., 254: 636 (1956).

5. Engle, M. A., Holswade, G. R., Goldberg, H. P., Lukas, D. S., and Glenn, F. Present problems pertaining to patency of the ductus arteriosus. I. Persistence of growth retardation after successful surgery. Pediatrics, 21: 70 (1958).

6. Falliers, C. J.: Treatment of asthma in a residential center: A fifteen-year study. Ann. Allergy, 28: 513 (1970).

7. Fisher. R. A.: Statistical Methods for Research Workers, Ed. 12 (Hafner Publishing Co., New York, 1954).

8. Garn, S. M., Rohmann, C. G., and Silverman, F. N.: Radiographic standards for post-natal ossification and tooth calcification. Med. Radiogr. Photogr., 43: 45 (1967).

9. Greulich, W. W., and Pyle, S. I.: Radiographic Atlas of Skeletal Development of the Hand and Wrist, Ed. 2 (Stanford University Press, Oxford, England, 1959).

10. Hansman. C. F., and Maresh, M. M.: A longitudinal study of skeletal maturation. Amer. J. Dis. Child., 101: 305 (1961).

11. Kerrebijn, K. F., and deKroon, J. P. M.: Effect on height of corticosteroid therapy in asthmatic children. Arch. Dis. Childhood, 43: 556 (1968).

12. McFadden, E. R., Jr., and Lyons, H. A.: Arterial blood gas tensions in asthma New Engl. J. Med., 278: 1027 (1968).

13. Prader, A., Tanner, J. M., and Von Harnack, G. A.: Catch-up growth following illness or starvation. An example of developmental canalization in man. $J$. Pediat, , 62: 646 (1963).

14. Reimer, L. G., Morris, H. G., and Ellis, E. F.: Growth of asthmatic children during treatment with alternate day steroids. J. Allergy Clin. Immunol, 55 : 224 (1975).

15. Roche, A. F., Davila, G. H., Pasternack, B. A., and Walton, M. J.: Some factors influencing the replicability of assessments of skeletal maturity (GreulichPyle). Amer. J. Roentgenol., 109: 299 (1970). 
16. Roche, A. F., and Johnson, J. M.: Comparison between methods of calculating skeletal age (Greulich-Pyle). Amer. J. Phys. Anthropol, 30: 221 (1969).

17. Schoen, E. J., Solomon, I. L., and Milkovich, L.: Bone age in short boys and tall girls. Amer. J. Dis. Child., 119: 252 (1970).

18. Tanner, J. M., Whitehouse, R. H., and Healy, M. J. R.: Standards for skeletal maturity based on a study of three thousand British children. II. The scoring system of all twenty-eight bones of the hand and wrist. (Institute of Child Health, University of London M.S., 1961).

19. Vaughan, V. C.: Growth and development. In: W. E. Nelson, V. C. Vaughan, and R. J. McKay: Textbook of Pediatrics, Ed. 9, pp. 44-5I (W. B. Saunders Co., Philadelphia, 1969).

20. Waddell, J. A., Emerson, P. A., and Gunstone, R. D.: Hypoxia in bronchial asthma. Brit. Med. J., 2: 402 (1967)

21. Wilson, A. F., Suprenant, E. L., Beal, G. N.. Siegel, S. C., Simmons, D. H., and
Bennett, L. R.: The significance of regional pulmonary function changes in bronchial asthma. Amer. J. Med., 48: 416 (1970).

22. Parental consent was obtained for the $X$-rays which were included in the routine diagnostic examination of all patients.

23. The author acknowledges her gratitude to Dr. Marion M. Maresh of the Denver Child Research Council for instruction in the assessment of skeletal age and for help and advice throughout the course of this investigation.

24. This study was supported in part by Grant GRS RR 05474 from the National Institutes of Health.

25. Requests for reprints should be addressed to: H. G. Morris, M. D., National Jewish Hospital and Research Center, 3800 E. Colfax Ave, Denver, Colo. 80206 (USA).

26. Accepted for publication March 25, 1975

\title{
Comparison of Electrophoretic Mobility and Membrane Sialic Acid Content of Erythrocytes from Adult and Umbilical Cord Blood
}

\author{
STEPHEN J. LUNER AND DOROTHY SZKLAREK \\ The Gwynn Hazen Cherry Memorial Laboratories, Department of Pediatrics, Hematology-Oncology Division, \\ UCLA School of Medicine, Los Angeles, California, USA
}

\section{Extract}

Determinations of cell electrophoretic mobility at low ionic strength and of ghost sialic acid content show that erythrocytes from umbilical cord blood and from adult donors are identical in these two glycoprotein-related properties. Using streak deflection electro-

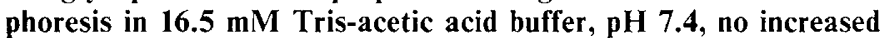
streak width indicating electrophoretic heterogeneity could be detected when mixed suspensions of adult and umbilical cord blood erythrocytes were compared with suspensions of adult cells alone. Sialic acid content of $100 \mathrm{nmol} / \mathrm{mg}$ protein were obtained for both populations of cells.

\section{Speculation}

Unlike cells involved in rapid proliferation, which carry higher negative surface charge densities than those which are nonproliferating, the umbilical cord erythrocyte exhibits the surface charge characteristics of a fully mature cell.

The bulk of the negative charge at the erythrocyte surface responsible for the electrophoretic mobility of the cell was shown by Cook et al. (1) and by Eylar et al. (4) to be due to sialic acid. Cells of the rare $M N$ variants $M^{\mathrm{g}}, \mathbf{M}^{\mathrm{k}}(9,12)$, Miltenberger classes $I I I$ and $V(9)$, as well as cells lacking the public En antigen $(5,9)$ and Tn polyagglutinable cells $(11,16)$, exhibit, in addition to their serologic abnormalities, aberrant values for membrane sialic acid content and electrophoretic mobility. In these abnormal cells, as well as in the case of neuraminidase-treated cells $(4,10)$, the percentage of decrease in sialic acid content corrsponds to the decrease in negative electrophoretic mobility. Treatment with proteolytic enzymes also decreases sialic acid, but it also unmasks new negatively charged components other than sialic acid $(10,14)$.

An increase in electrophoretic mobility for erythrocytes from umbilical cord blood over the adult value has been reported by Rottino and Angers (13) as well as by Hollan et al. (17). However, Uhlenbruck and Heggen (17) have found cord blood erythrocyte surface glycoproteins indentical with those of adults in the amount of sialic acid contained in glycopeptides removed from the cell membrane by Pronase and in the serologic reactivity of their receptors containing sialic acid.

The present study of cord blood erythrocyte electrophoretic mobility and sialic acid content was undertaken to investigate the maturation from fetal to adult surface properties. It was found, however, upon studying a large number of samples of both types of cells, that there were no differences between the two populations in both of these glycoprotein-related properties.

\section{METHODS}

Erythrocytes from blood collected in EDTA tubes were stored in modified Alsevers solution and used within a week of drawing the blood. After four washings with phosphate-buffered saline, $0.5 \mathrm{cc}$ packed cells was used to prepare ghosts for sialic acid determination, while a second aliquot was taken for electrophoretic mobility measurements.

Two washings with $40 \mathrm{ml} 5 \mathrm{mM}$ Tris buffer, $\mathrm{pH} 8$, were sufficient to prepare ghosts free of visible hemoglobin from the $0.5 \mathrm{cc}$ 